\title{
THE EFFECT OF PLUGGING STORM PIPE CULVERT ON HEAD I
} (II)

Mahmoud Ghonem, Magdy Mowafy, Amgad El-Ansary, Hamdy El-Ghandour

\begin{abstract}
Debris flows affecting highways and plugging a storm culverts always cause overtopping of the road by sliding debris causing increase of the total head losses. The experimental study in this research aims to examine the effect of the cross sectional plugging percentage on the total energy (total head) loss. A storm pipe culvert was tested for five different discharges ( $Q=8.5$ to 38.8 lit. /sec), different submergence ratios ( $\mathrm{Y} 2 / \mathrm{d}=1.0,1.5$, and 2.0$)$, fixed longitudinal plugging length $((\mathrm{Lr})=50 \%)$, and different cross sectional plugging percentage $(\mathrm{Ar}=(0 \%, 10 \%, 30 \%, 50 \%)$. Results of the study estimate the risk of road failure, predict implications of relatively high flows, and identify culverts that need to be replaced. Increasing the cross sectional plugging (Ar) from $10 \%$ to $50 \%$ led to rise in the increasing factor of the relative energy head loss by about $103 \%$ at $\mathrm{Y} 2 / \mathrm{d}=1.0$, and by about $136 \%$ at $\mathrm{Y} 2 / \mathrm{d}=2.0$ with the average pipe Froude number $\mathrm{Fp}=0.41$.
\end{abstract}

